\title{
The level of participation during the development of a mobile application for home-based healthcare data in a developing context: An actor-network theory perspective
}

\author{
Retha de la Harpe \\ Faculty Informatics \& Design, Cape Peninsula University of Technology, South Africa
}

\begin{abstract}
The context of this study is home-based healthcare in a South African resource-restricted community. The research case involved the design and development of a mobile care data application, created to assist community caregivers in their professional activities. However, the development principles of a suitable mobile application for feature phones (limited functionality) in this context are not fully established. A participatory design approach was employed using a design science research in information systems strategy. Data was collected during the co-design sessions with the active participation of the caregivers to design and develop a suitable mobile application to capture process and report care data. The activities of the caregivers in practice and the design and development activities were observed. It was observed, conversely, that the level of participation of all stakeholders differed significantly during the process. It was especially observed that the designer and end-users were less involved in the actual development of the prototype. These differences may have an influence on the end product/result. Actor-network theory (ANT) was used to offer a new perspective on the development processes, concepts and structures. ANT has not been used extensively in development studies and may provide a mechanism to describe how the human and non-human actors formed relations as they participate in these processes through translation moments. ANT also considers the 'black-boxed' aspect of IT artefacts during development as a single node of the network that may need to be opened up. Considering the alignment of such networks, the coordination, devices and passages during the four translation moments provide valuable insights in the design and development of technology products. This paper will consider these elements in more depth. The socio-economic factors of the developing context influenced the complex socio-technical development of the mobile application. The role of technology artefacts to assist with the development of new IT artefacts is more complex in a developing context since there are not enough mobile artefacts that could be used as examples to guide the developers. This aspect, as well as the lower digital literacy of the end-users, influences their level of participation during the design and development phases. There seems to be a large gap between mobile development in the global North versus that in the global South.
\end{abstract}

KEYWORDS: home-based healthcare, participatory design, mobile application, mobile development, actor-network theory

CATEGORIES: H.5.2, K.6.3

\section{INTRODUCTION}

The adoption of a participatory approach for the development of a mobile application in a resource-restricted setting is challenging. The respective users in this environment are mostly exposed to feature phones with limited functionality [1. Moreover, there were relatively few advanced mobile applications available that could serve as examples of how to develop interventions in such cases. This paper discusses the design and development of a practical application for use in a South African home-based healthcare setting. This application was envisioned to assist caregivers with capturing, reporting and sharing of patient data. The

Email: Retha de la Harpe delaharper@cput.ac.za investigators made use of a participatory design approach in the initiation and creation of the application prototype.

The setting is typical of a developing context and as such the study considered the issues of Information Systems Development for Development (ISD4D). The formation of a local network of actors designing and developing an IT artefact, that has the potential to improve the situation of caregivers, is considered. In development studies, a global network of actors, provide the space and resources for projects with the aim to improve the socio-economic well-being of resource-restricted communities [2]. The evaluation of the eventual use in practice of the practical application discussed in this paper falls outside the scope of this paper and further research would be required to also consider the developmental factors that are 
outside the project to consider a global network.

The approach followed by this research study was to introduce technology only if there is a need for it and then only with the active participation of the endusers. The perspective is of social embeddedness which assumes the construction of new techno-organisational structures within a given local social context 3 . The focus of this paper is not on the potential benefit of the technology solution but rather to reflect on the level of participation during the design and development phases. In development, and especially with information communication technology (ICT), the participatory methods should be framed by discourses on the social embeddedness of ICT with a focus on the importance of local factors in technology appropriation rather than just on ensuring product quality and relevance 4 . After reviewing the literature of co-designing with communities, David, Sabiescu \& Cantoni 4 identified five themes relevant for co-design with development, namely stakeholders, context, ownership, social learning and sustainability. Of note is social learning as a process of knowledge advancement through exchanges as the different stakeholders interact during the co-design 4 . When there is a large design reality gap then the proposed ICT system will most probably fail since it will not function in practice as anticipated [5]. Heeks suggests [5] that the participation of the local users; appropriate technology mix based on the local context; alignment to local development goals; and consideration of project risks during the design should result in more successful ISD4D projects.

Caregivers participated satisfactorily within the initial product design phase. However, they were mostly passive during the development phase of the application. These observations of the extent of participation by the different actors introduced an intellectual puzzle: what was different between the design and development phases? The author therefore considers 'design' and 'development' as the two primary phases of the application prototype. Other project phases - e.g., an initial needs analysis and the final testing phase - are considered elsewhere as discrete cycles [6] 7]. The approach of Diaz Andrade and Urquhart 8 was selected for analysing the design and development phases, i.e., the translation process. Based on this approach the objective for this paper is to investigate whether the actants' interests were sufficiently considered throughout the design and development phases of the mobile care data application. Secondly, the author considers whether the modus operandi of the project was appropriate in order to establish the networks of participation in a developing context.

Actor-network theory (ANT) was considered as a possible analytical lens to establish some insights in the formation of stable networks aligned around mutual interests. It was decided to separate the design and development phases to focus on the differences between these two phases since the level of participation changed after the first phase. The symmetry aspect of ANT provides a possibility to follow both human and non-human actors - referred to as 'actants' — as equal participants. ANT is a descriptive lens, telling the stories of 'how' relations between actants assemble or not 9 .

Actor-network theory (ANT) has been used in information systems research but not much with development studies 2. Heeks suggests 2] that ANT can provide new insights by describing processes in detail to study the emergence of actor-network structures as well as allowing non-humans an active materiality to expose the role they play in development. This will help to understand agency, process and relations among development actors better. It is this aspect of ANT that is used in this study to understand the role of the non-humans during the design and development of the mobile application, namely the IT artefacts, in terms of their level of participation and their responses during the translation moments.

This study draws from social and artificial sciences where, in the case of social sciences, knowledge creation is subjective and about human behaviour. The caregivers will use their knowledge and common sense during their care activities by giving meaning to them whilst responding to the context of their environment, in this case typical of a developing context. The concept of artificial sciences, introduced by Simon [10] is knowledge about how things could be ('utility') through a design process as opposed to natural sciences where knowledge is about how things are ('truth'). The moment the designed artefacts are being used, the focus changes to social sciences where the behaviour of people using the artefacts is considered. Examples of IT artefacts during design are models, constructs, methods and instantiations [11.

The theoretical contribution for this study is based on a framework proposed by Kuechler and Vaishnavi [12] for studies in design science research in information systems (DSRIS) although in this study with consideration of the developing context. They based their framework on Gregor's 13 taxonomy of information systems theory. Furthermore Gregor published with several colleagues on the theoretical contribution of design science research in information systems based on the initial work of March and Smith 14 and Hevner et al. 11. The general activities of the DSRIS framework are: the construction of the artefact; the gathering of data on the functional performance of the artefact or the evaluation; and reflections on the construction process. This study's focus is only on the construction activity which is the design and development of a mobile application for care data. During the construction of the IT artefact prescriptive knowledge is generated based on two constructs, namely, the problem and solution constructs in both the instance and abstract domains 15]. Iivari [16] suggests that prescriptive knowledge is its own form of knowledge that cannot be reducible to descriptive knowledge. Descriptive knowledge is composed of observations, measurements classified into accessible forms [17]. Prescriptive knowledge of the design is presented as design principles of both form and function. During the evaluation and reflection activities descriptive knowledge is generated 
that Gregor and Baskerville [18, refer to as the following research activities for descriptive theorizing: study of the artefact in use and test of knowledge of the artefact in use. The reflective questions they suggest for extracting theory for the different design components will be used to suggest the theoretical contribution of this paper. Although design science research has been used in information systems before [11, publications, specifically about the theoretical aspect of this approach, have only been published more recently.

\section{RELATED RESEARCH}

\subsection{Mobile health (mHealth)}

mHealth is a component of eHealth and to date, no standardised definition of mHealth has been established [19]. The Global Observatory for eHealth (GOe) defines mHealth as medical and public health practice supported by mobile devices, such as mobile phones, patient monitoring devices, personal digital assistants (PDAs), and other wireless devices. In terms of healthcare, there is a need for a healthcare system that is usable anytime, anyplace and by anyone authorised [20] 21. mHealth enables the connecting of different communities to exchange data and experience using mobile technologies. It also supports the shift from treating acute and chronic diseases to disease prevention and wellness promotion. South Africa has a large number of lay health workers and most of the population also have mobile phones or access to mobile phones and these phones can therefore be used to improve service delivery of community health care services: this is known as mobile health for community based services or mHealth4CBS 22. Leon and Schneider 22 identified a few challenges for mHealth4CBS and the two relevant to this study are the poor documentation of mobile applications and best practices as well as the challenge of identifying and using affordable open-source options.

Drivers for mHealth applications are socioeconomic rather than technical [23] 24]. A singlesolution focus on mHealth should be replaced with it being an extension and integrator of underlying health information systems that support, e.g., the point-ofcare for health workers 25. Mecheal and Searle [25] further suggest that mHealth applications should be interoperable and integrated with provider systems linking the most remote health worker with the most appropriate sources of information when and where needed. The individual care data at the home and facility level can then be aggregated to serve as a basis for health information.

Even though the drivers for mHealth applications are socio-economic rather than technical, the application is still regarded as an IT artefact. The artefact is an embodied structure, where its structural properties include the pattern, rules and resources inscribed during the design and development process resulting in a relatively immutable output [26] 27]. This may assume that technologies embody specific stable structures [28] or being regarded as black boxed. However Orlikowski
28] argues that such assumptions of technological stability, completeness and predictability with a predefined anticipated use are not true in practice where people modify technologies to fit their use in practice. Software developers use existing technologies to develop new technologies as applications, e.g., database management systems, web services, etc. These technologies with their anticipated in-use inscriptions may then be used differently in practice - the 'appropriation' of an artefact is the combination of embodiment in-design and enactment in-use in a specific situation, or at least to what extent the technology allows it to be used differently [27 28. An mHealth application is the result of the design and development process based on the identified anticipated use with the use of other technology artefacts.

\subsection{Participatory design}

Participatory design (PD) is about both the process of design - with the active participation of all participants - and research. The outcomes of design includes artefacts, systems, services, and the like. The outcome of research is knowledge 29. PD allows for participants' interpretations to be taken into account by envisioning, shaping and transcending the activities until all agree with the outcomes. The participants in $\mathrm{PD}$ are equal in a network aligned around a mutual interest to create new designs and knowledge. Mosavel, Simon, Van Stade and Buchbinder [30] argue that the input and involvement of community stakeholders are essential for successful research. Community-based participatory research $(\mathrm{CBPR})$ seeks, in addition to knowledge creation, action and change as its primary goals. Winning the trust of respective communities is integral in the co-design philosophy. Health interventions, therefore, need to address the multiple anxieties and lived reality of that community 30, 31. The participation process for this study started with forming a trust relationship with the home-based healthcare service provider and the participation design sessions were conducted in their work space to cater for their lived reality.

Hussain, Sanders and Steinert 32 identify the following differentiating circumstances when designing with the participation of marginalised people: human; social, cultural and religious; financial and timeframe; and organisational. When considering social development during $\mathrm{PD}$, attention needs to be given to the participatory process (Byrne \& Sahay, 2007). Byrne and Sahay's 33 findings for the PD of a communitybased health information system indicate that it is necessary to go beyond end user participation to also consider the persons affected through the delivery. In the case of healthcare services the patients will be the indirect beneficiaries of any interventions that will assist caregivers in their care services. They also suggest that a multilevel and multisectoral approach should be adopted and that reflective practices to develop capacity should be enhanced. Bailur 31] concludes that community participation in developing contexts is more complex than has been reported in the literature. 
The level of participation is not always the same during all the phases of a project (extent); it may include all the users or representatives of users and the content may include technical, social aspects or both 34. Maail 34 further suggests that user participation should correspond to the conditional factors of the context of the system development that should rather be regarded as the optimal level of participation than a high degree of participation. In this study it was practical for the caregivers to participate corresponding to the conditional factors of the mHealth application design and development.

It is important to understand the work processes on a clinical level before developing IT solutions for the complex cooperative and interdisciplinary work associated with home-care services [35]. A participatory approach allows for the active participation between the healthcare professionals and developers to obtain a common understanding of the work processes in practice. Hochheiser and Lasar [36] caution against a focus purely on the design of a user interface that will result in a lack of considerations of the social, political, ethical, and societal implications of computer systems.

Mobile development is faced with the following challenges: to create user interfaces accessible to differently-abled users; to handle the complexity of developing applications across multiple mobile platforms; the need to consider context-aware applications; and to deal with the uncertainty of specifying requirements [37. Most mobile applications are still developed by small teams who rarely use any formal development processes 38 . Developers did limited organised tracking of their development efforts and that the existing body of knowledge is mostly pragmatic with guidelines and code examples [38. This could pose a problem to novice developers who need to consult with existing practices and examples and this is even more problematic if the existing limited development guidelines and code are not suitable for a developing context. It is important to consider the context (hardware, input, capability, platform, conventions of each platform and environment) and the implementation where the designs and code are delivered to support the user experiences, in this case the caregivers during their service provision [39]. During execution time performance needs to be considered. An information system's development and implementation should be regarded as a complex sociotechnical process and even more so in a developing context 40].

All of the above aspects are considered in this paper in an attempt to understand the perceived difficulties observed during the design and development of the mobile application.

\subsection{Actor-network theory}

Actor-network theory (ANT) evolved from the work by Callon and Latour at the Ecole des Mines in Paris during the 1980s [41] 42. Important contributions are also made by Law [9] 43. ANT proposes a theory that does not privilege either humans (actors) or non-human actors (actants) over the other and denies that purely technical or purely social relations are possible. Other recent works on ANT are how Heeks and Stanforth 44] use ANT to provide details about the process of technological change by 'opening' the black box of such a change. De Albuquerque, Cukierman, Marques and Marques 45] consider how technology moves from the global North to the global South where such technologies are often black-boxed based on their use in the global North. The issue then is to consider how one can distinguish between questions to do with the materials of development and those to do with the strategy of development. This study considers an mHealth application, with the use of technologies typically developed in the global North, to be developed and used in a developing context in the global South. The network of actors is considered with a specific focus on the translation as they enter (or resist entering) the network.

Translation has its origin in the social studies of science and deals with how statements become facts and how that only happens when other people accept and/or use 46. The creation of facts is a collective process - translations are the result of recording the viewpoints of the different participating actors of the network [6]. This process necessarily entails interactions and negotiations between actors before any kind of agreement can be reached about common definitions and meanings 47. Successful translation occurs when all the 'voices' speak in unison, i.e., when all agree to the same aligned interest. By studying the translation process, it is possible to determine to what extent the different actors are identified and consulted. Translations may have implications for the role and relationships of the actors within the network when the impact of the organisation and/or stakeholders is considered as the actors react to changes [46].

Problematisation is the first translation moment and can be regarded as 'how to become indispensable'. The focal actor, the actor from whose vantage point the process is conducted, establishes an interest that is primarily of interest to the focal actor, but could be useful to other actors. The second translation moment is to build an interest ('interessement') which refers to how the allies are locked into place in order to form a network and to strengthen new actors' links with the network. The third translation moment is enrolment which refers to how other actors decide to become part of the network. This means that other actors are convinced that they can benefit by joining the network and this happens when individual actors align their own interests to that of the focal actor. They may do this willingly or may be cajoled into joining the network. The final moment of translation is when actors who have previously been enrolled, become spokespersons in their own right of the focal actor's interest. While it is also possible that during this stage some actors may leave the network if they feel that their interests can no longer be sufficiently aligned with the interest of the network, the ultimate goal of institutionalisation becomes more of an achievable goal.

It is possible that a translation moment may fail. 
From a research perspective, this is also important because explanations and insights into how and why it failed could lead to a deeper understanding of the interaction processes involved. ANT allows us to model mistranslation as a possible intentional betrayal and the reasons for this may be relevant for the research to identify important obstacles.

\section{PARTICIPATORY DESIGN AND DEVELOP- MENT OF A MOBILE CARE DATA APPLI- CATION}

\subsection{The context of home-based healthcare}

Home-based healthcare in South Africa addresses the overwhelming need for services related to the high incidence of HIV/AIDS, TB and other poverty-related conditions experienced in resource-restricted communities [48, 49] 50] 51]. The public healthcare service is responsible for healthcare service provision to the majority of the population. Formal healthcare facilities, however, cannot meet the demand for these services [1. Home-based healthcare addresses this demand and is mostly offered by non-government organisations. Home-based healthcare institutions rely on external donations since patients in most cases cannot afford to pay for delivered services (Ibid.). Home-based healthcare services are provided by informal caregivers with basic training. In some cases, they are supported by professional nurses.

The recording of patient data is still paper-based and very time-consuming [1]. Caregivers are generally semi-literate and many of their patients are illiterate. There is limited electricity in these communities but most people have a mobile phone or have access to one. These are mostly feature phones with limited functionality 7].

\subsection{Research methodology}

The research strategy considered for this study is design science research with a participatory approach. The research was started with an ethnographic study of home-based healthcare services in a developing context [1. During this stage a relationship was built with the NGO providing the care services and only when this study was completed was the design process started. Data for the design was collected during the problematisation and ideation phases with the use of design probes. Other data collection methods were observations and open-ended interviews. Several service design methods were used during the different participatory co-design sessions. For the purpose of this paper, the co-design stage with the low fidelity (lo-fi) prototype is considered as the design concept for designing the mobile user interface and navigation between the different screens [6]. A lo-fi prototype, in this case a paper mock-up of the typical mobile phones used by caregivers, was used to facilitate discussion of user interface concepts and design alternatives [52].

The data was analysed by extracting the design principles and reflection on the design sessions and methods used. The qualitative data was coded and categorised to identify themes that were then interpreted. In addition, the author, who supervised the students with their post-graduate studies for this case as well as the practical project of designing and developing the mHealth application, did a meta-analysis at an 'etic' level of the different activities [53].

The practical design and development was done by a team of intern students. The team consisted of an anthropologist, designer and IT analyst, all three masters' students. The rest of the team was compiled of IT students. All the members of the team were novices since they did not have any work experience. The IT interns were not only novice developers but also came from a developing context background.

\subsection{The participatory design phase}

A community in the Western Cape of South Africa was selected for this case. The research team built a relationship with a home-based care NGO (hospice) in the area. This proved challenging; the staff was sceptical of the many promises made by different groups to improve their situation without their expectations being met. The team explained that it was there to work towards possible solutions that could improve their work conditions. The participatory design process was explained to them to convince them of their active role in the co-design process. The main objective of the design phase was to identify a real need and to then co-design a possible solution with the active participation of the caregivers.

Using a lo-fi prototype saves valuable time and costs of programming fully electronic prototypes and is a useful mechanism to present abstract concepts to users with low digital literacy as a mock-up of possible ideas. The caregivers were able to design their own dialogue and suggest navigation options. In Figure 1 an example of a lo-fi prototype where the suggested dialogue is given. The dialogue in the sequence of the five screens is as follows:

1. Caregiver login

2. Enter patient number

3. Patient details

4. Observations:
Temp ${ }^{\circ} \mathrm{C}$
$\mathrm{H} / \mathrm{R} \_\mathrm{BPM}$

5. Care plan:

Clean wound

Ointment

Dressing $\overline{\mathrm{X}}$

\subsection{The development phase}

The development was done by IT interns from the local university who were mostly third and fourth year students working in an incubation hub and paid a monthly stipend. This hub was used as an interactive design space, where top students from different disciplines, levels, and cultural frameworks worked together on developing mobile applications for real-life problems. 


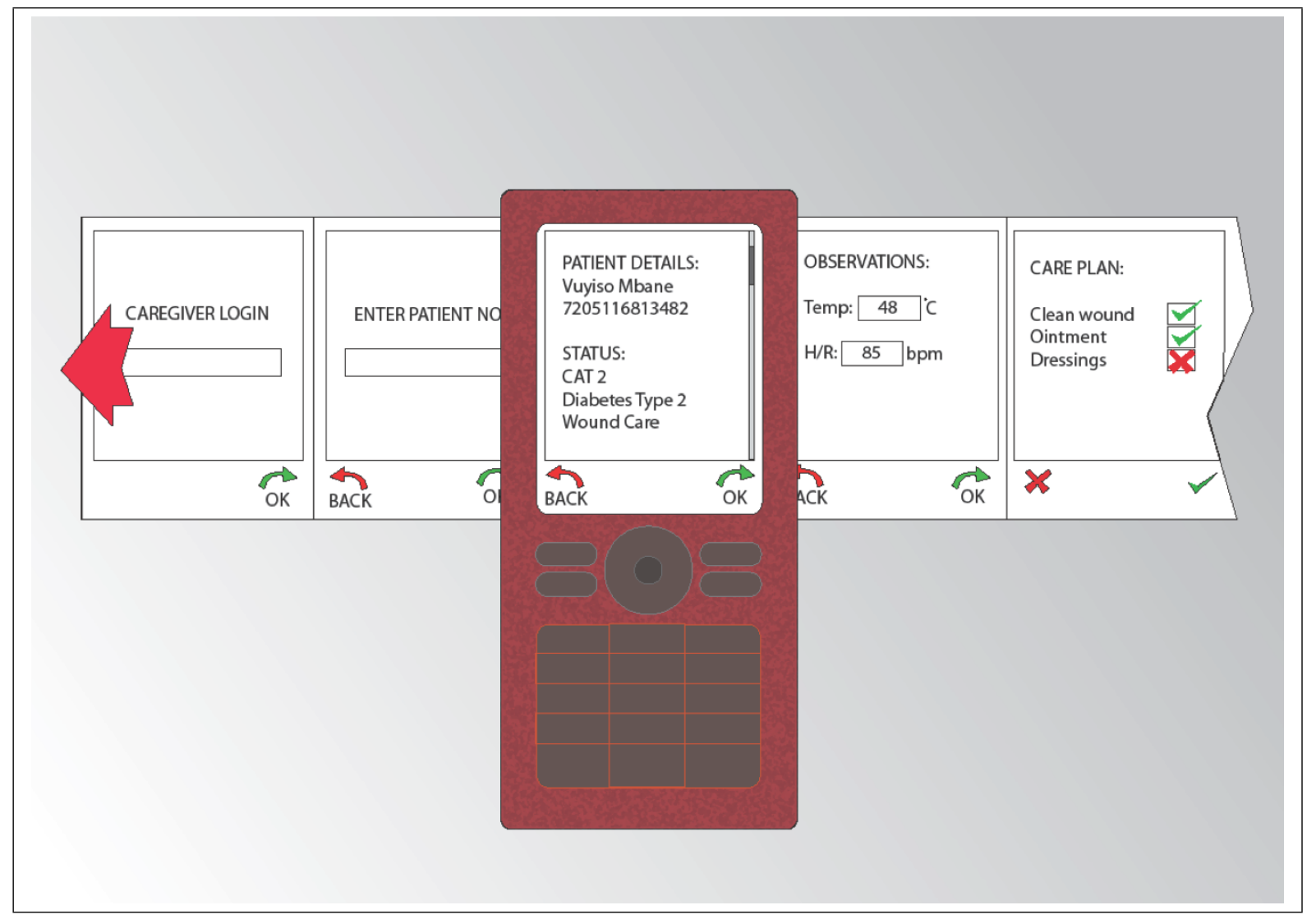

Figure 1: Prototyping scenario

Funding was obtained to develop a practical application. The developers converted the designs created during the design phase into code for the proposed mobile application to capture, report and share patient care data. The interns had no prior experience and were novices in the project. Since the developers were from a developing context, they were familiar with the socio-economic challenges experienced by the caregivers. The developers were involved from the beginning of the design process as active participants.

\section{USING ANT AS AN ANALYTICAL LENS}

The term actant is used for both human actors and technology actants when discussing their role in the actor-network. Where necessary a distinction will be made. The following actants are considered for the design phase: caregiver, designer, developer, current paper forms (care record, care daily report, care monthly report); lo-fi prototype as the design concept; care tasks; and work tasks (design mobile interface; and recall care data recording). The focal actor role was mostly performed by the designer who explained the different methods as well as facilitating the co-design sessions. The developer could speak the language used by most caregivers (Xhosa) and was therefore able to act as a translator when necessary. This helped to overcome the language barrier 32 .

The main actants for the development phase were: developers, designer, caregivers as the end-users; the development platform; database; designs; specifications; hand held devices; source code; documentation; prototypes; development and testing tasks; work tasks (design technical components, interfaces, etc.); code; test; and document. Mobile technology includes handsets, computers, servers, software and bandwidth connectivity, different systems or protocols for communicating signals that could include GPS, GPRS, USSD, and Bluetooth 22.

\subsection{Problematisation}

The designer explained the need to design the mobile user interface to the caregivers participating on behalf of the others and became the gatekeeper of the codesign process. The aligned interest was to design the user interface together and the lo-fi prototype was introduced as a useful actant to help them with the co-design process. The designer also convinced the developers that the proposed co-design method would result in a better design for the mobile user interface. The current paper forms used for recording the care details of the patients were also introduced as actants for the co-design process. The care tasks and work tasks to design the mobile user interface and how they recalled the recording of care data also became actants required for the co-design process.

During the development phase the designer acted as the focal actor introducing the design to the developers as part of aligning the interest to develop the mobile prototype. The question posed to the developers was how to develop the mobile prototype based on the design to simplify the capturing and reporting of 
patient data by caregivers. The participation of the developers during the co-design phase allowed them to already have their interests aligned to the problem. The technology actants were required for converting, through a series of translations, the design into the mobile prototype. It was already clear at this stage that the mobile prototype would consist of many parts to support the user interface design as could be seen from the number of technology actants required. These different parts of the prototype - e.g., user interface, database, backend code, and the like - are all separate technology actants interacting with each other as well. The developers became the designer's main allies since they participated in the co-design phase and were therefore familiar with the design created as an outcome of the design phase.

\subsection{Interessement}

The designer planned the co-design sessions carefully and had a few meetings with the relevant stakeholders to convince them of the importance of the co-design session. After the co-design sessions, the designer reflected on the design process and designs created to plan for the next sessions. There were no actants who were not interested in the proposed session and this is probably because the decision for the mobile application was taken by the facility management and the co-design sessions were arranged to be during regular training sessions. No specific incentives were used and it was observed that the caregivers enjoyed the participation process since it provided them with recognition for the important work they are doing. The other actants from the development team and design concepts were properly introduced and relationships formed through the interaction sessions. The facility manager and care-coordinator became valuable allies since they supported the project and even participated in the co-design process from time-to-time. The use of the lo-fi prototype allowed current care data recording practices to be challenged and for new possibilities to be introduced and considered that were easy for the caregivers to relate to their potential use.

The designer not only put together a convincing case for the developers but the outcome of the co-design already created an expectation by the end-users (the caregivers) of how they could benefit from the proposed mobile care data application. Although the technology actants were identified to be crucial for the development of the mobile prototype, the purposes for which they were originally designed were not completely aligned with the purpose for how they would be used in this case. In the original design the manners in which they were to be used were inscribed in them and since mobile development was new, these actants' purposes were not well-aligned to mobile development. It became increasingly more difficult for the designer to interact with the technology actants since he was not familiar with the technical aspects of development. At this point the end-users (the caregivers) were also unable to participate because they were lost with the technical aspects of the process. The developers took over the role of focal actors with the designer and end-users 'leaving' the network. This aspect is important and will be discussed further on.

\subsection{Enrolment}

It was not necessary to persuade and convince the actants to participate in the co-design sessions since they related well to each other and the lo-fi prototype made it possible for them to interact with an abstract concept of interface design in a real manner allowing them to make suggestions. The developers also related well to the method which was new to them and interacted with the caregivers without dominating the co-design session. The roles of all the participants were clear and the lo-fi-prototype made the bargaining and compromising process easier to manage.

The enrolment of the actants in the development network was problematic. The identified technology actants were necessary for the development of the mobile prototype but because they were designed with specific inscriptions for specific uses that were difficult to adapt to mobile development in this context, they, in a way, resisted enrolment. These technology components were typically developed as IT artefacts to assist with development but did not seem to be appropriate for a developing context. This resulted in a continuous process of negotiations between the developers and technology actants that could be seen as processes of translations for the developers to learn how to use these actants and for the actants to respond in ways that made it possible for them to be used for developing the mobile prototype. In addition to the essential technology actants the developers also continuously experimented with other technologies therefore replacing some of the technology actants with others. These replacements resulted in the need for new enrolment strategies, i.e. the new technology actant had to be considered for the problem, being 'made' interested before being enrolled into the network. These negotiations seemed to exclude the designer and end-users from the network because they did not seem to understand the 'technology' language used by the developers interacting with the technology actants. The developers continuously had to learn how to use the different technologies and were unable to translate that to the designer and end-users.

\subsection{Mobilisation}

The design network became stable after all the actants progressed through the translation moments and the designer became the spokesperson for the network. He was able to do this since he understood the purpose of the method and was able to present the user interface design as the outcome of the co-design sessions. He was able to translate the perceived care data recording activities on paper to the anticipated activities in the mobile application. The caregivers who did not participate in the co-design sessions were well-represented because their care activities were standardised by the 
facility. They also mostly had the same background and training.

It took a long time for the development network to become stable and most of the negotiations between the developers and technology actants were invisible in terms of the progress during the development phase. The emulator software specifically was a technology actant that resisted its use since the emulation that worked on the computer did not work in the same way on the handheld mobile devices. Even code that worked on one device, e.g., Nokia, did not work the same way on another device, e.g. Samsung. Writing code for feature mobile phones was extremely difficult because there were no other examples of how this could be done. It seemed that smart phones quickly became the preferred mobile devices in the global North and that may be the reason for the lack of examples for feature phones. Testing was a challenge due to connectivity issues, differences in mobile phones (there were no standards), transferring data to the backend system, etc. The continuous replacement of some of the technology actants to experiment with them resulted in the network remaining unstable with difficulties for the actants to remain enrolled. This resulted in a situation where it took a very long time for the network to reach a mobilised stage. There was not a specific spokesperson for the development network since different interns worked on different parts of the development until a project coordinator was formally appointed. This person then became the spokesperson for the network. The end-users and designer, who were no longer enrolled in the development network, had to be re-enrolled to test the usability of the mobile prototype. It was a new negotiation process that required again an alignment of interest. An example was when the developers illustrated the prototype and it did not work because of connectivity, version and server issues resulting in the end-users being perplexed when the developers used a 'technocratic' approach: 'It does work, you just press here and then...'. It seems as if the end-users never re-enrolled in the development network and this problem now has to be addressed during the deployment phase with a specific strategy to enrol the end-users again.

\section{DISCUSSION}

\subsection{Alignment}

According to Diaz Andrade and Urquhart 8, alignment is to what extent actants agree to translation. Through these translations the actants move towards an agreed aligned interest. The stability of the network depends on how well the interests are aligned to the interest that describes the purpose of the network. It can also be regarded as when the network grows with continuously more actants being enrolled than actants leaving the network.

In the case of the design network it was clear that the translations were supported by the use of the lofi prototype - this actant played an important role in assisting with the translation process between the end-users and designer that resulted in the creation of another actant, the design of the proposed mobile prototype. The outcome of the design network not only resulted in a stable well-aligned network but also in the enrolment of an actant that was created based on the successful translations of the other actants, namely the design for the mobile interface. One can therefore conclude that the co-design process was successful and that design concepts are useful actants that can assist with translation of abstract concepts such as converting the recording of patient data on a paper care record to a recording it electronically with a mobile application. Another finding is that a design was created as a good representation of the anticipated use as a result of successful alignment of the actants of the design network. The embodiment in-design is therefore close to the possible enactment in-practice.

The alignment of the development network was problematic with the technology actants making translations more difficult. The alignment between the developers and technology actants required many translations, some mistranslations when the conversion of the design into the prototype just did not work. The technology actants are the results of the creation of these artefacts based on the uses that are inscribed into them - this also was the result of a process of translations and thus alignment but for another purpose. Using these actants for mobile development required them to be used differently to their original intended use and that resulted in the need for many translations between the developers and technology actants to align them to the conversion of the mobile prototype based on the design of the prototype. The processes, interests, identities, values, etc., inscribed in the technology components used for developing the mobile prototype were not suitable for a developing context. The reason why the end-users and designer were excluded from the alignment process of the development network was that the translations required by the development process were just too technical to them. Again the mobile prototype is a new actant that is the result of the alignment of the other actants, and how good it is will depend on how well the prototype represents the design of the mobile interface as the representation of the anticipated use.

It is possible that the technology actant can influence the outcome of the development of the mobile prototype if, for example, the backend technical design cannot support the navigation required by the user interface design. The design of the mobile interface only represents the part of the interface visible to the end-users as that is the only part that concerns them directly. In reality this design has to be supported by additional technical designs of the other parts of the mobile prototype, e.g., database design, activity diagrams, workflow designs, etc. These technical designs are introduced during the development phase as the outcome, i.e., new actants of the network, of the interactions between the developers and the technology actants required to do these designs. These technology parts of the mobile prototype are essential 
for the mobile application to work and all contributed to the formation of the development network as they are enrolled.

The translation of the design into the mobile prototype is complex and requires many translations between the developers, technology actants and designer. The new actants created through the alignment process are also technical and may not always be a good representation of the design.

\subsection{Coordination}

Coordination is the degree to which the interpretive flexibility is restricted by rules or conventions [8]. In the case of the design network the interpretive flexibility was influenced by the lack of technology knowledge of the end-users rather than rules and conventions of the design process. Participatory design implies that the design process is started with no pre-conceived idea of the solution but to allow the end-users to determine the pace and direction of the process with the designer being more in the role of facilitator suggesting possibilities with the use of design concepts. The use of the lo-fi prototype made the interpretation easier because the caregivers could relate to it without feeling intimidated by technology. This allowed them to experiment with different options for the navigation, displayed text and options for entering the care-patient data. The designer was given the opportunity to learn the 'language' of the caregivers in their own environment and to observe their work practices - this provided him with a better understanding of the possible solutions for their data capturing problems.

The co-design process allowed for interpretive flexibility by continuously responding to the environment in which the process took place. Although the design process was not influenced by rules and conventions, the manner in which the caregivers capture the patient data and the type of data recorded and reported are restricted by the rules and conventions of their work practices that again have to comply to the rules and conventions of the healthcare professional practices as well as to the legal requirements of the authorities to which the home-based healthcare service provider reports.

In the case of the development network the interpretive flexibility was influenced and mostly restricted by how the rules and conventions were inscribed into the technology actants for their specific uses that could not easily be adapted for mobile development. The definitions of patient data, data transmission protocols, coding and other standards, etc., have to comply with the rules and conventions of the agreed standards of software development. These rules and conventions do not only have to be considered but are inscribed into the different technical designs and the mobile prototype, i.e., the new technology actants will have these inscribed into them. There were also not yet any standards for mobile development that could be used by the developers.

\subsection{Devices and passages}

The main activities of home-based healthcare are to provide care services to patients at their homes. A sub-activity is the recording, reporting and sharing of care patient data which is still paper-based in most communities. The care patient data represents the details of the patient's diagnosis, observations and care activities and can be regarded as the substantive device for aligning a network around home-based healthcare. During the design phase the representation of the care data, i.e., the design of interface to the data can be regarded as the substantive device to align the network around the interest to facilitate easier data recording and processing. The means supporting the design is the design concept, in this case the lo-fi prototype and the procedural device to facilitate coordination and communication around the design is co-design activities to design the navigation of the identified data elements according to the work practices associated with the care data recording of the patient.

During the development phase the actants are enrolled into the network around an interest to convert the design of the care data interface into a mobile care data prototype. The substantive device in this case is the representations of the caregivers anticipated care data processes and the means for this are the different technology actants that support the coding into the mobile prototype. The procedural devices are the interactions between the developers, the technical tools and each other to develop the code for the prototype.

\subsection{Applying ANT}

ANT provides the mechanism to follow the actants of the design and development phases to establish to what extent they participated in the respective networks. This provided insights in the design and development processes and specifically how the technology actants made the participation easier as in the case of the lo-fi prototype in the design network and more difficult in the case of the development network. This could be contributed to the fact that mobile development is not yet matured as indicated in the literature and that the learning process made participation with the technology actants more difficult - one can assume that knowing how to use the tools (technology actants) should make the development easier. The social learning during the design phase applied to all the participants - the designer and developers learnt more about the caregivers' data capturing practices and the caregivers learnt more about the possible technology solution. Social learning during the development phase was mostly applicable to the developers who learnt more about the use of the technology actants but the learning could not be shared with the designer or end-users. The challenge here seems to be the difficulty in communicating the technology actants' roles to the actors without the technological background. The developers involved in ICT solutions for developing contexts may not have the necessary technical knowledge or access to materials that could guide them 
and therefore may struggle to use the technology components in the way their use is already inscribed. It is then possible that the design-reality gap may increase when the technology and environmental constraints influence the translation from the design to the ICT solution.

Another reason for the challenges experienced during the development phase is that the inscriptions of the technology artefacts used for the development, may not support the way they should be used in mobile development. The participation approach worked well during the design phase and all the actants actively participated in the process. The technology actants had to be adapted to be used in the particular context that was constrained by socio-economic factors. The lack of involvement of the caregivers, as the representatives of the community considered, not only affected the development process negatively but also influenced the research outcomes even though the lived reality of the community was inscribed in the design outcome [30]. It may be necessary to consider the involvement of participants without the necessary technical knowledge to see how they can participate during the development stage. It is possible that the level of participation during the development may be lower due to the nature of the development process and in this case it may be necessary to determine the optimal level of participation of all participants to proceed with the process without the end-users becoming totally uninvolved.

In both the design and development networks new actants were created as the result of the participation of the other actants and it can be concluded that the level of participation will determine the quality of these new actants (design and mobile prototype). Having this view can assist with dealing with the context when similar solutions are considered for other contextsthe focus then on the participatory process where the designs and prototypes are actants of new networks where the outcome could be different.

Responding specifically to the use of ANT in developing studies, it was possible to describe the design and development processes in detail to show how the actor-network structures emerged [2]. It was also possible to expose the roles that the IT artefacts play in development. The IT artefacts that could not so easily be adapted to the developing context as the design probe did, resulted in several difficulties experienced during the development of the mHealth application. Contributing to this problem was the inexperienced developers who could not easily learn how to use the IT artefacts in development. In a developing context there will often be less experienced developers who do not have the luxury of being sent for expensive training by their companies or who are not able to work in teams with more experienced developers. The black box nature of IT artefacts used during development influences the manner in which they enrol in the network since the purpose for which they were designed may not be well aligned to that of developing a mobile application in a developing context.

It was also interesting to note that the spokesper- son of the network during the mobilisation translation moments changed from the designer to a developer and it will be interesting to see if the spokesperson of the eventual solution would be a community representative. Studying the level of participation and especially the 'failed' translation moments should provide more insights on aspects that need attention as can be seen by the alignment problems of the development network.

Table 1 presents the key findings of the alignment, coordination, devices and passages of the design and development networks with possible implications.

\section{THEORETICAL CONTRIBUTION}

This study considered the following cognate disciplines: information systems, development studies and design. It used a DSRIS framework to allow for theory development. The DSRIS framework does not provide for development studies and the suggestions of Gregor et al. 13 [15, 18, also do not consider development studies specifically. There is therefore a need to develop a framework that also provides for development studies, maybe a DSRIS4D? The use of ANT as a suitable lens for development studies as suggested by Heeks [2] is an attempt to also include the insights gained from this analysis.

The framework proposed by Gregor et al. [15] is now used to extract design theory from this study for the following design theory components: 'purpose and scope', 'principles of form', and 'principles of function'.

The problems the researchers originally perceived were that care services were hampered by the manual data recording, many mistakes were made when completing the paper forms, and this data recording process was very time-consuming. The problem was not identified by the caregivers since they work in a resource restricted setting that does not allow for 'niceto-have' solutions. Their current paper-based system works and supports the care services. In a developing context it may often be the case that people accept a situation because there are not resources to improve the situation. The proposed mobile application is not a novel solution but developing a solution that is appropriate for their situation provided a utility value - a mobile application could be useful and has the potential to improve the quality of care services in developing contexts and result in better quality data for decision making. The design concept was the mobile care data application (CDA) and the focus with the caregivers' participation was on the user interface. The concepts came from a developing context and it was possible to reach a proof-of-concept stage. The evaluation in practice was outside the scope of this paper. There are potential problems that could influence the actual implementation of the mobile application that were identified from the ethnography study, and these are: connectivity issues, cost of the mobile application, potential target of crime (e.g., if criminals hurt caregivers to steal their mobile phone), etc.

The principles of form are the material properties built into the artefact to enable it to achieve its pur- 
Table 1: An ANT analysis of the participatory design and development phases of a mobile care data application

\begin{tabular}{|c|c|c|c|}
\hline $\begin{array}{l}\text { ANT analytical } \\
\text { construct }\end{array}$ & Design network & Development network & Possible implications \\
\hline Alignment & $\begin{array}{l}\text { - A design concept allows for } \\
\text { the assembling of good rela- } \\
\text { tions between the design ac- } \\
\text { tants that results in a strong } \\
\text { alignment between all the ac- } \\
\text { tants. } \\
\text { - A participatory approach pro- } \\
\text { vides for a situation where all } \\
\text { the actants have the ability to } \\
\text { actively participate in the de- } \\
\text { sign process. }\end{array}$ & $\begin{array}{l}\text { - The technology actants in- } \\
\text { fluenced the level of participa- } \\
\text { tion with the developers having } \\
\text { complex relations around the } \\
\text { translation of the design into } \\
\text { the mobile prototype and with } \\
\text { the designer and end-users be- } \\
\text { coming inactive. } \\
\text { - Alignment is difficult with dif- } \\
\text { ferent levels of complex trans- } \\
\text { lations required. }\end{array}$ & $\begin{array}{l}\text { The degree of participation in- } \\
\text { fluenced how the design and } \\
\text { development of the care data } \\
\text { processing were done. During } \\
\text { the design phase the degree of } \\
\text { agreement between the actants } \\
\text { was high whereas during the } \\
\text { development phase it was low. }\end{array}$ \\
\hline Coordination & $\begin{array}{l}\text { - The rules and conventions of } \\
\text { home-based care services are } \\
\text { embedded in the work practices } \\
\text { of the caregivers that were rep- } \\
\text { resented in the design of the } \\
\text { mobile data application. } \\
\text { - The co-design process al- } \\
\text { lowed for flexible interpreta- } \\
\text { tions of the possibility of the } \\
\text { mobile application and with } \\
\text { the designer more in the role of } \\
\text { a facilitator. }\end{array}$ & $\begin{array}{l}\text { The interpretation flexibility } \\
\text { was restricted by the rules and } \\
\text { conventions of how these were } \\
\text { inscribed into the technology } \\
\text { actants used to develop the so- } \\
\text { lution as well as the accepted } \\
\text { standards of software develop- } \\
\text { ment. }\end{array}$ & $\begin{array}{l}\text { Understanding of the rules and } \\
\text { conventions of the work prac- } \\
\text { tices in a particular context are } \\
\text { well represented when a partic- } \\
\text { ipatory process is used to pro- } \\
\text { vide active participation of the } \\
\text { end-users who are knowledge- } \\
\text { able about their rules and con- } \\
\text { ventions. } \\
\text { There seems to be an insuffi- } \\
\text { cient understanding about the } \\
\text { rules and conventions of devel- } \\
\text { opment as well as how these } \\
\text { are inscribed in the technology } \\
\text { actants. }\end{array}$ \\
\hline $\begin{array}{l}\text { Substantial } \\
\text { devices }\end{array}$ & $\begin{array}{l}\text { The representation of the care } \\
\text { data as part of the proposed } \\
\text { interface. }\end{array}$ & $\begin{array}{l}\text { The representations of the care- } \\
\text { givers' anticipated care data } \\
\text { processes in the form of techni- } \\
\text { cal designs and code. }\end{array}$ & $\begin{array}{l}\text { Identifying the substantial de- } \\
\text { vices of the design and develop- } \\
\text { ment networks provided a bet- } \\
\text { ter understanding of the key } \\
\text { purposes of these networks. }\end{array}$ \\
\hline Material devices & $\begin{array}{l}\text { The design concept, namely the } \\
\text { lo-fi prototype. }\end{array}$ & $\begin{array}{l}\text { The technology actants sup- } \\
\text { porting the conversion of the } \\
\text { care data processes into the mo- } \\
\text { bile prototype. }\end{array}$ & $\begin{array}{l}\text { Consideration of the material } \\
\text { devices provided insights in the } \\
\text { interplay with the material and } \\
\text { procedural devices. }\end{array}$ \\
\hline $\begin{array}{l}\text { Procedural } \\
\text { devices }\end{array}$ & The co-design activities. & $\begin{array}{l}\text { The interaction between the de- } \\
\text { velopers with each other and } \\
\text { with the technology actants } \\
\text { and the designs. }\end{array}$ & $\begin{array}{l}\text { Insights in how the design } \\
\text { and development proceeded } \\
\text { and the underlying assump- } \\
\text { tions were obtained by consid- } \\
\text { ering how the actants inter- } \\
\text { acted. }\end{array}$ \\
\hline
\end{tabular}

pose. The principles of form observed are the menu design based on the users' preferences for the data capturing sequence; data elements on the screen should be minimal and easy to navigate; and familiar terminology should be used. Rather use drop-down lists than entering text; use, where possible, short-cut keys, e.g., '\#3. Care plan'; the use of directional buttons (up, down, left and right) for selection of options; minimal text entry. The contextual conditions observed to enable the emergence of the desired affordances are the type of mobile devices used by the caregivers that is typical of a developing context, e.g., phone features. The data collected are the data observations typical of a developing context: e.g., 'Has the patient taken the medicine?', 'Is there enough food?', 'Are the children looked after?', etc. The caregivers, as the user group, perceive the functional affordances of the artefact that represent their care activities. The active level of participation of the caregivers provides the justificatory knowledge that the material properties should achieve the artefact's goals.

The principles of function are difficult to present since the artefact was never implemented to be used in practice. During the testing phase it was difficult for the users to see how the artefact could be used in practice since there were technical problems, e.g., there was a problem for the mobile phone to connect to the server, there were version problems. It was clear that the gap between the lo-fi prototype and actual mobile application was too big since the users were not partic- 
ipating during the development stage. The necessary actions to bring about the desired outcomes are to find a way to make the development activities more visible to the users without exposing them unnecessarily to the technical aspects of development.

Responding specifically to the use of ANT in developing studies, it was possible to describe the design and development processes in detail to show how the actor-network structures emerged [2. It was also possible to expose the roles that the IT artefacts play in development. The IT artefacts could not so easily be adapted to the developing context as with the design probe, resulting in several difficulties experienced during the development of the mHealth application. Contributing to this problem was the inexperienced developers who could not easily learn how to use the IT artefacts in development. The black box nature of IT artefacts used during development makes it difficult to 'open' it to adapt components for more appropriate use. It therefore seems that it is necessary to develop an IT 'toolkit' with IT artefacts that are more suitable for the developing context or at least have a repository with such tools with sufficient guidelines to use them.

Reflecting on this research the following were observed: it is important to build a relationship with the user group or representing organisation before starting with the design process. There are far too many empty promises made to communities in need or too many solutions with limited utility value 'given' to them. Once the relationship is strong the users must become active co-designers of their own solutions with the designer/developer more in a facilitating role. It is important to design the solution first to a point where the possible solution is a good representation of what can be expected when it is completed before starting with the development of the IT artefact. Developers should be involved in the co-design sessions to obtain a good understanding of the required solution but also to learn more about the users' mental processes. Specific IT artefacts that are suitable for a developing context should be developed to be used as developing tools during the development process. These development tools should be more flexible, easy to be used and shared by less experienced developers.

\section{CONCLUSION}

Actor-network theory provided a sufficient mechanism to establish how actants participated during the design and development phases of a prototype for a mobile care data application and the stories of the relations between the actants and the level to which these relations were formed were part of this descriptive study. Design science research is a suitable research strategy and the participatory design a suitable approach for these kinds of development for information systems. This approach provides for the considerations of the context by giving the community representatives a voice. Even though the evaluation and reflection activities of DSRIS were not done, there are already sufficient insights in the design and development activities to contribute towards the development of mobile applications as part of an information system in a developing context.

Mobile development has many challenges and recounting the stories of how mobile applications are developed, and especially the role of the technology actants and how all the actants interact with each other, can provide valuable insights. This is especially valuable in a developing context where there are limited resources. When the designers and developers are immersed in the developing context they obtain a better understanding of the local context and therefore the perspective of social embeddedness seems to be appropriate for the developing contexts. The dynamic of role allocation for participation also seems to be an important aspect of the formation and sustaining of sociotechnical networks. The use of suitable design probes increases social learning and communication but this seems to be more complex for the use of technology components during development. It seems that the design-reality gap increases during the development phase.

The research question posed for this paper can be answered as follows: the interests of the actants during the design phase were sufficient but less sufficient during the development phase. The modus operandi to establish the network using participatory design was appropriate for the design phase but did not work so well during the development phase when both the designer and end-users became inactive due to the technical nature of participation. Further research is required to obtain a better understanding of the reasons for the level of participation during the development phase and how to deal with technology actants and to determine the optimum versus high level of participation. Furthermore the investigation of the role of coordination of the rules and conventions during development will provide more insights into the difficulties experienced during the development of software in general, and mobile applications in particular, a developing context.

Further research is also required to focus more on the interactions between the actants for mobile development, the role allocation during participatory design and development, the factors leading to an increase in the design-reality gap, the translations during the iterations of development, and the inscriptions of the technology components.

\section{ACKNOWLEDGMENT}

INDEHELA-ISD4D Project: 'A holistic information systems development approach for societal development'. Funded by the Academy of Finland, 2010-2015.

\section{REFERENCES}

[1] I. Van Zyl. "Mutual isolation and the fight for care: An ethnography of South African home-based healthcare contexts." Journal of Health Informatics in Developing Countries, vol. 5, no. 1, 2011. 
[2] R. Heeks. "Development studies research and actornetwork theory". Centre for Development Informatics, Institute for Development Policy and Management, SED, Manchester: University of Manchester, 2013.

[3] C. Avgerou. "Discourses on ICT and development". Information Technologies $\&$ International Development, vol. 6, no. 3, pp. pp-1, 2010.

[4] S. David, A. G. Sabiescu and L. Cantoni. "Co-design with communities: A reflection on the literature". In J. Steyn and A. Van der Vyver (editors), Proceedings of the 7th International Development Informatics Association Conference, pp. 152-166. 2013.

[5] R. Heeks. The ICT4D 2.0 manifesto: Where next for ICTs and international development? University of Manchester. Institute for development policy and management (IDPM). Development informatics group, 2009.

[6] A. Delen. Service design challenges in home-based health care in the Western Cape: A case study. Masters thesis, Cape Peninsula University of Technology, 2010.

[7] I. Van Zyl and R. de la Harpe. "AT-HOME 2.0: A collaboration model for informal learning in homebased healthcare". Journal of Universal Computer Science, vol. 18, no. 3, pp. 429-453, 2011.

[8] A. D. Andrade and C. Urquhart. "The affordances of actor network theory in ICT for development research". Information Technology 8 People, vol. 23, no. 4, pp. 352-374, 2010.

[9] J. Law. "Actor network theory and material semiotics". The new Blackwell companion to social theory, pp. 141158, 2009.

[10] H. A. Simon. The sciences of the artificial, vol. 136. MIT press, 1969.

[11] A. R. Hevner, S. T. March, J. Park and S. Ram. "Design science in information systems research". MIS quarterly, vol. 28, no. 1, pp. 75-105, 2004.

[12] W. Kuechler and V. Vaishnavi. "A framework for theory development in design science research: multiple perspectives". Journal of the Association for Information systems, vol. 13, no. 6, pp. 395-423, 2012.

[13] S. Gregor. "The nature of theory in information systems". Mis Quarterly, pp. 611-642, 2006.

[14] S. T. March and G. F. Smith. "Design and natural science research on information technology". Decision support systems, vol. 15, no. 4, pp. 251-266, 1995.

[15] S. Gregor, O. Müller and S. Seidel. "Reflection, abstraction and theorizing in design and development research". 2013.

[16] J. Iivari. "A paradigmatic analysis of information systems as a design science". Scandinavian Journal of Information Systems, vol. 19, no. 2, p. 5, 2007.

[17] S. Gregor and A. R. Hevner. "Positioning and presenting design science research for maximum impact". MIS Quarterly, vol. 37, no. 2, pp. 337-356, 2013.

[18] S. Gregor and R. Baskerville. "The fusion of design science and social science research". In Information Systems Foundation Workshop, Canberra, Australia. 2012.

[19] M. Kay. "mHealth: New horizons for health through mobile technologies". WHO Global Observatory for eHealth, vol. 3, 2011.
[20] I. Junglas, C. Abraham and B. Ives. "Mobile technology at the frontlines of patient care: Understanding fit and human drives in utilization decisions and performance". Decision Support Systems, vol. 46, no. 3, pp. 634-647, 2009.

[21] J. E. Katz and R. E. Rice. "Public views of mobile medical devices and services: A US national survey of consumer sentiments towards RFID healthcare technology". International journal of medical informatics, vol. 78, no. 2, pp. 104-114, 2009.

[22] N. Leon and H. Schneider. MHealth 4 CBS in South Africa: A Review of the Role of Mobile Phone Technology for Monitoring and Evaluation of Community Based Health Services. Medical research council of South Africa (MRC). Health systems research unit, 2012.

[23] F. Mirza, T. Norris and R. Stockdale. "Mobile technologies and the holistic management of chronic diseases". Health informatics journal, vol. 14, no. 4, pp. 309-321, 2008.

[24] A. C. Norris, R. Stockdale and S. Sharma. "A strategic approach to m-health". Health informatics journal, vol. 15, no. 3, pp. 244-253, 2009.

[25] P. Mechael, H. Batavia, N. Kaonga, S. Searle, A. Kwan, A. Goldberger, L. Fu and J. Ossman. Barriers and gaps affecting mHealth in low and middle income countries: Policy white paper. Columbia university. Earth institute. Center for global health and economic development (CGHED): with mHealth alliance, 2010.

[26] S. Gregor and J. Iivari. Designing for mutability in information systems artifacts. Canberra: ANU Press, 2007.

[27] I. Widjaja and S. Balbo. "Embodied and enacted: The Janus faces of structure-of-use". In Proceedings of the 4th Nordic conference on human-computer interaction: changing roles, pp. 421-424. ACM, 2006.

[28] W. J. Orlikowski. "Using technology and constituting structures: A practice lens for studying technology in organizations". In Resources, co-evolution and artifacts, pp. 255-305. Springer, 2008.

[29] C. Spinuzzi. "The methodology of participatory design". Technical Communication, vol. 52, no. 2, pp. 163-174, 2005.

[30] M. Mosavel, C. Simon, D. Van Stade and M. Buchbinder. "Community-based participatory research (CBPR) in South Africa: engaging multiple constituents to shape the research question". Social Science $\mathscr{E}$ Medicine, vol. 61, no. 12, pp. 2577-2587, 2005.

[31] S. Bailur. "The complexities of community participation in ICT for development projects: The case of Our Voices". In Proceedings of 9th International Conference on Social Implications of Computers in Developing Countries. 2007.

[32] S. Hussain, E. B.-N. Sanders and M. Steinert. "Participatory design with marginalized people in developing countries: Challenges and opportunities experienced in a field study in Cambodia". International Journal of Design, vol. 6, no. 2, pp. 91-109, 2012.

[33] E. Byrne and S. Sahay. "Participatory design for social development: A South African case study on community-based health information systems". Information Technology for Development, vol. 13, no. 1, pp. 71-94, 2007. 
[34] A. G. Maail. "User participation and the success of development of ICT4D projects: A critical review". In Proceedings of SIG GlobDev 4th Annual Workshop. 2011.

[35] M. Hägglund, I. Scandurra and S. Koch. "Using scenarios to capture work processes in shared home care." Studies in health technology and informatics, vol. 130, pp. 233-239, 2006.

[36] H. Hochheiser and J. Lazar. "HCI and societal issues: A framework for engagement". International Journal of Human [\# x02013] Computer Interaction, vol. 23, no. 3, pp. 339-374, 2007.

[37] J. Dehlinger and J. Dixon. "Mobile application software engineering: Challenges and research directions". In Workshop on Mobile Software Engineering. 2011.

[38] A. I. Wasserman. "Software engineering issues for mobile application development". In Proceedings of the FSE/SDP workshop on Future of software engineering research, pp. 397-400. ACM, 2010.

[39] A. Charland and B. Leroux. "Mobile application development: web vs. native". Communications of the $A C M$, vol. 54, no. 5, pp. 49-53, 2011.

[40] N. T. Mengesha. "Sociotechnical dynamics in IS development in organizations: The case of a resourceconstrained and competitive context". Information Technologies $\&$ International Development, vol. 6, no. 3, pp. pp-33, 2010.

[41] M. Gallon. "Some elements of a sociology of translation". The science studies reader, p. 67, 1999.

[42] B. Latour. Science in action: How to follow scientists and engineers through society. Harvard university press, 1987.

[43] J. Law. "Notes on the theory of the actor-network: Ordering, strategy, and heterogeneity". Systems practice, vol. 5, no. 4, pp. 379-393, 1992.

[44] R. Heeks and C. Stanford. "Technological change in developing countries: Opening the black box of process using Actor-Network Theory. Working Paper no. 5", 2013. URL http://www.cdi.manchester.ac uk/resources/ant4d

[45] J. P. de Albuquerque, H. L. Cukierman, I. d. C. Marques and P. H. F. Feitosa. "Challenging the ontology of technoscientific artefacts: Actor-Network Theory in the context of developing countries". In Understanding Development Through Actor-Network Theory International Workshop. 2011.

[46] E. A. Whitley and A. Pouloudi. "Studying the translations of NHSnet". Journal of Organizational and End User Computing (JOEUC), vol. 13, no. 3, pp. 30-40, 2001.

[47] C. Warzynski. "An actor-network approach to leading technological change: Implementing a new technology at a prominent US research university". The network approach: building organisations and society. Amsterdam: Van Gorcum, 2006.

[48] H. Coovadia, R. Jewkes, P. Barron, D. Sanders and D. McIntyre. "The health and health system of South Africa: historical roots of current public health challenges". The Lancet, vol. 374, no. 9692, pp. 817-834, 2009 .

[49] S. Erasmus. "Health in South Africa: Shocking Statistics". Published in Health24, 2009.
[50] E. Jack, L. Jenkins and D. Enslin. "Home-based care: caring for people in the community-challenges and opportunities: case study". South African Family Practice, vol. 52, no. 6, pp. 531-533, 2010.

[51] N. A. Shozi. Factors affecting the use of mobile devices for remote data collection in home community based care. Masters thesis, Nelson Mandela Metropolitan University, 2012.

[52] T. Memmel, H. Reiterer and A. Holzinger. "Agile methods and visual specification in software development: a chance to ensure universal access". In Universal Acess in Human Computer Interaction. Coping with Diversity, pp. 453-462. Springer, 2007.

[53] C. P. Kottak. Mirror for humanity: A concise introduction to cultural anthropology. McGraw-Hill New York, 1996. 